\title{
HOW TO BEST FRAME A DESIGN BRIEF TO MAXIMIZE NOVELTY AND USEFULNESS IN IDEA GENERATION
}

\author{
G. Koronis ${ }^{凶}$, A. Silva, J. K. S. Kang and C. Yogiaman \\ Singapore University of Technology and Design, Singapore \\ $\bowtie$ georgios_koronis@sutd.edu.sg
}

\section{Abstract}

This paper aims to identify factors that influence creativity, and strives towards understanding the effect of representations, namely abstract and concrete design outcomes. Three conditions are compared; a control group, an abstract group, and a group provided with various example solutions. The implications of this work can strongly impact the formulation of design briefs, where the goal is to stimulate the creativity of design brief outcomes and examine their relationship to product awareness.

Keywords: idea generation, conceptual design, empirical studies

\section{Introduction}

Design is a cross-disciplinary concept complex in its very nature. Yet despite intricateness, design a solution-focused process is gaining prominence, as evidenced is being taught as a central subject in disciplines such as engineering, architecture, and industrial and graphic design (Lawson, 2006), and the latter playing a pivotal role in society through the creation of novel and appropriate solutions. A review of the literature shows that while creativity is certainly not a new concept, it has yet to be defined empirically (Runco and Jaeger, 2012).

Creativity is central to human activity (Shai et al., 2013) and involves the production of original, and potentially workable, ideas to solve a problem (Bourgeois-Bougrine et al., 2017). Creative ideas rarely arise out of nothing. As our earlier studies show, students, devise novel ideas with the aid of various stimuli. As a result, new concept ideas emerge from a set of example solutions that designers are exposed to and which encourage them to draw from tried-and-tested concepts while discouraging them from thinking of new or distantly related concepts (Kang et al., 2018).

A literature review of creativity adduces that while it is not a new concept, it remains empirically undefined (Runco and Jaeger, 2012). Howard et al., (2010) asserted the positive influence of stimuli, on the generation of appropriate and original ideas during brainstorming sessions. These studies explore the relationship between creativity as a developmental tool, the creativity of engineering students' project outcomes (Bourgeois-Bougrine et al., 2017), the impact of visual stimuli in the experiment space, and the creativity of design students' concept sketches (Goldschmidt and Smolkov, 2006). Given creativity's pivotal role across society through the generation of novel and appropriate solutions; the pedagogy of creativity in engineers and designers is an area of interest for tertiary institutions.

Educational institutions' interest in creative design is amplified by the periodic constraining effects designers broadly experienced during the ideation process (Genco et al., 2012). Regardless of the type 
of fixation encountered, the escalated concerns are highlighted as both for professionals and student engineers who experience difficulties during the ideation and innovation process. In the study of Viswanathan and Linsey (2012) external representations were introduced to facilitate ideation in an attempt to break the fixation cycle.

Although creative projects often start with a design brief, not a lot of study has been dedicated on how framing briefs can impact designers' creative outputs in terms of novelty and usefulness. Thus, we assessed creativity using multiple measures like drawing exercises, questionnaires, and sketch evaluations. In our analysis, we paired the sketches evaluations with a survey response to explore if varying stimuli permutations intricate relationships with their creative outcomes while accounting for a student's first-hand experience with mobility devices.

To the best of the authors' knowledge, our research is among the first to experimentally manipulate brief framing while simultaneously considering interactions of students' awareness with their design outcomes. For example, Viswanathan and Linsey (2012) showed that there is a need to study physical examples to better understand their impact on idea generation as physical examples have different effects on idea generation. However, the effect is not decisive. We have also observed that during the design process, designers do search for additional information for inspiration and interact with physical samples to understand the mechanisms or usability of existing solutions. Thus, we hope that studying these two formats can contribute to understanding the effects of examples and their impact when encountered in the idea generation process.

\section{Background}

\subsection{Design briefs}

In a design project, design briefs are typically introduced at the beginning of the process (Camburn et al., 2017) to formalize the expectations the outcome is meant to meet, thereby setting the tone for the project and guiding its direction (Koronis et al., 2019). Briefs are aimed at steering the designer through the process so their structure has a critical influence on the generation of creative ideas (Carlgren et al., 2016; Sosa et al., 2018). Briefs are often developed by a project manager or design team in consultation with the "client" as a condensed articulation of desired results and targeted group needs.

\subsection{Use of abstract vs concrete presentations and their Impact on Ideation}

When designers are looking for inspiration, they tend to prefer using visual representations (Vasconcelos and Crilly, 2016). However, visual aids come with the downside of cognitive fixation, inducing the copying of features (Goldschmidt and Smolkov, 2006; Johnson et al., 2016). In the study by Goucher-Lambert et al., (2019) these kinds of inspirational stimuli provoke analogical reasoning or other closely related mental processes. Ideally, the designer will then analyze those inspirations and discard them depending on their suitability (Gonçalves et al., 2016).

The impact of abstract representations on creativity is a topic of interest across disciplines. In pedagogy, the transfer of ideas between domains using graphic simulations can be improved by presenting problems in an abstract, idealized form (Goldstone and Sakamoto, 2003). More abstract functional representations have also been shown to be effective as stimuli in reducing cognitive fixation (Studer et al. 2016) and fostering the generation of new ideas (Zahner et al., 2010; Linsey et al., 2010).

Similar to the study of analogical distances, creative outcomes are examined with regard to participants' fidelity of external representation (Vasconcelos and Crilly, 2016). Accordingly, the fidelity of external stimuli refers to participants' notion that stimulus is abstract or concrete. Degrees of stimuli fidelity have also been described in psychology as simulation, with low-fidelity stimulus taking a textual form and high-stimulus fidelity represented as video-based items (Lievens et al., 2012). In engineering design literature, findings suggest that abstract brief requirements improve idea associations between domains (Linsey et al., 2012) while concrete brief features are easier to recognize, and thus easier to replicate (Vasconcelos et al., 2017).

Concrete terms refer to detailed, explicit examples of things that can be directly perceived with the senses, while abstract terms depict ideas, attributes and relationships requiring inferences using mental 
representations from language and context (Marschark and Paivio, 1977). For this study, an abstract brief refers to low-level stimulus fidelity and the physical examples provided (considered as concrete representations) had high levels of specificity relating to the product.

On the one hand, when problems are too concrete and specific, the transfer becomes difficult; on the other hand, if there is no "domain instantiation" representing problems too abstractly reduces the production of successful outcomes (Holyoak and Thagard, 1989). A good abstract representation, according to Zahner, "will conform to problem constraints while increasing the range of associations and domains". Of the studies reviewed, the use of abstract stimuli improved novelty by limiting detailed specifications and replacing them with more general function-based terminologies in the domain. For instance, to reduce fixation in the design problem description, more abstract functions expressed as troponyms (action-specific verbs) and hypernyms (more generic action terms) such as "transmitting energy to object or separating outer structure from inner material" were used instead of tangible, concrete terms expressed as hyponyms (specific grouping terms) like "using a press to crush and remove the peanut shell" (Linsey et al., 2010; Heckler, 2010).

\section{Research objectives}

University students participated in an empirical study aimed at promoting idea generation when designing a product and investigating the efficacy of different brief formats in the early stages of student design projects. Though the existing studies discussed earlier focused on separately testing the effects that each one of a variety of examples have on the creative outcome, there has yet to be a study that combines a number of examples in the exploration of design on creative outcomes. To address this gap, we attempt to determine which stimuli can be amalgamated to constitute an evocative design brief while exploring creativity among academic individuals.

From our survey questionnaire (Q1 and Q2 in Appendix), we sought to ascertain whether student's stimulation by the design brief is related to product awareness. Despite the diverse findings from earlier experimentation, little academic study has been devoted to the coherent and purposeful investigation of design briefs and associated representations, especially in an educational environment. To address this topic, we have devised the following research questions (RQ):
RQ1. Which representations - abstract or concrete - enhance or improve the creativity indices of design outcomes in concept sketch generation?
$R Q 2$. Does previous knowledge and familiarity with a design task enable students to generate more creative ideas?

\section{Experimental methods}

This study examined the work produced in an engineering course for juniors at a university course by 65 first-year undergraduate students $(\mathrm{M}=41 ; \mathrm{F}=24$, with an average age of 20). Each class of students was assigned randomly to an experimental group so that the participants spread is assumed to be reasonably homogeneous.

A questionnaire was designed to seek demographic particulars, the allocation for the study and ascertained their familiarity with the requested design task (product awareness). Participants had to answer the question: "Have you ever used or assisted someone to use a mobility aid(s)/device(s) for the disabled?" (see Appendix for descriptive stats).

To investigate the influence of stimuli on the design outcomes, each class was given the same control brief with various permutations of stimuli of abstract and concrete nature, in the below setting:

- Control: This group received a succinct problem description (Figure 1).

- Abstract: This group received a generic brief including abstraction propositions (Figure 2).

- Physical Example: This group received a number of example solutions to interact with before the control brief was given (Figure 3).

The groups were then tasked with a short sketch activity. Participants in all the groups were given identical material packages containing an A3-size paper and pens to complete their sketches. All briefs were deliberately crafted to let participants explore a broad range of concepts so they would not be 
unduly penalized for lack of knowledge in any specific domain. The external motivation was controlled as participants were informed that incomplete sketches would bear no influence on their academic standing or performance.

Next, participants were tasked with individually sketching their solution concepts for "a device to improve mobility for low-income persons with physical disabilities." The students were given 15 minutes to develop three concepts and instructed to be as creative as possible with the connotation that in our experiment, three creativity metrics are used to score designs. It was not incumbent on the subjects to have extensive prior experience solving analogous problems. We assumed that having personally used an assistive device or having helped someone use a mobility device were situations that at least several students would have experienced before.

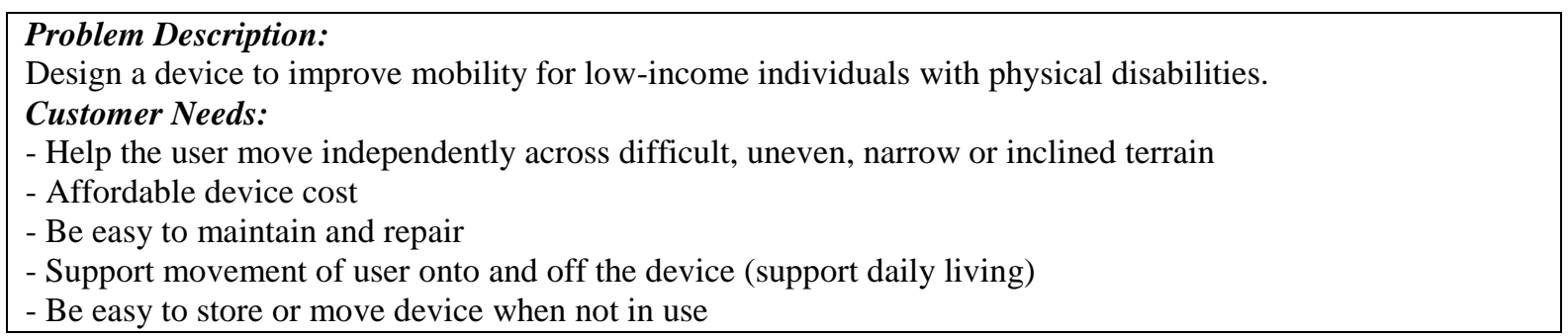

Figure 1. Baseline brief

The device should:

- Help the user to move independently across difficult, uneven, narrow, or inclined terrains

- Affordable device cost

- Be easy to maintain and repair

- Support movement of user onto and off the device (support daily living

- Be easy to store or move device when not in use

To assist you in developing your design, consider the following abstractions:

- Transferring energy from a system or device to people who have little or no energy

- Transferring signals from person to system or device

- Effecting a controlled displacement of an object in any axis

- Acquiring within a person's resource capability

- Restoring something to its original state

- Transforming an entity to fit storage dimension.

Figure 2. Abstract design brief

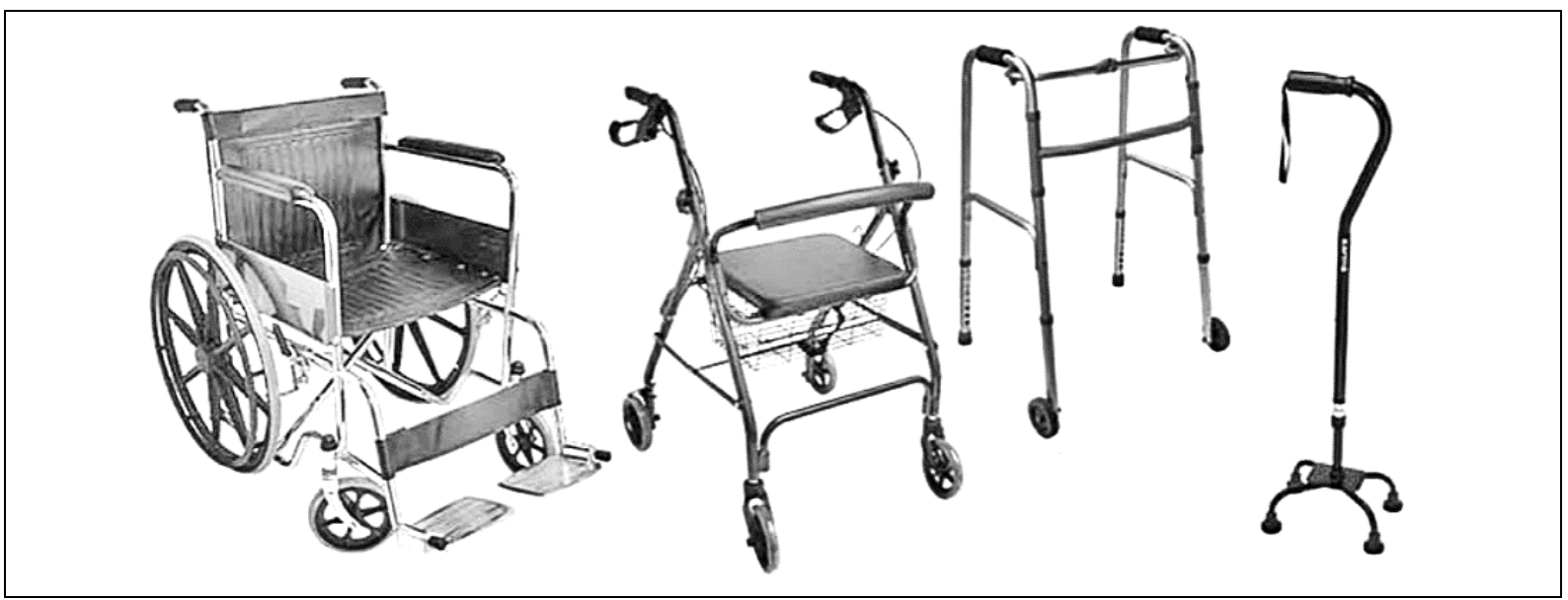

Figure 3. Photos of physical examples provided to the participants in the group with the physical brief 


\subsection{Creativity metrics}

The creativity of design outcomes can be assessed in many ways. Amabile (1996), has included the constructs of novelty and appropriateness (usefulness, correctness, valuableness) when applied to a product or response. More recent literature in the field of design science suggests a plethora of metrics for evaluating creative outcomes from an ideation task. Those include novelty, variety, quantity (fluency), quality (Shah et al., 2003) workability, relevance and specificity of ideas (Dean, 2006). Kampylis and Valtanen (2010) suggest that creative products must be novel (original, unconventional) and appropriate (valuable, useful) while Runco and Jaeger (2012) state that there is a general agreement that originality and usefulness as necessary components of creativity.

Our study employed the assessment technique detailed by Amabile, however, with a modified version of usefulness. Novelty was defined as the extent to which the design is different from usual forms of mobility. Usefulness encapsulated multiple facets as our interest to use a modified version of the usefulness metric was to include a broader definition by a series of factors of usefulness (Dean, 2006), as such Usefulness is the mean value of Implementability and Effectiveness based on equal weighting.

\subsection{Design outcome assessment}

The sketches evaluations were conducted with reference to the consensual technique of creativity assessment (Amabile, 1996). This technique is based on the ratings of a group of "expert judges", validated as a reliable and consistent evaluation practice among expert judges (Baer, 2008; Amabile, 1996). Using 1-to-5 Likert type items, the judges graded according to the rubric of Table 1. We further assume that the judges shared similar understandings of all creativity metrics to a reasonable degree. Three list styles have been predefined in the template: bulleted list numbered list and lettered list. It is suggested not to use more than three list levels.

Table 1. Creativity metrics rubric with examples

\begin{tabular}{|c|c|c|}
\hline Novelty & Level /Example (1 out of 5) & Level /Example (5 out of 5) \\
\hline \multirow{2}{*}{$\begin{array}{l}\text { The extent to which the design } \\
\text { is different from the usual way } \\
\text { of mobility }\end{array}$} & Entirely similar & Entirely different \\
\hline & i.e. Copy of existing product & i.e. Idea is a real surprise \\
\hline \multicolumn{3}{|c|}{ Effectiveness (sub-metric for Usefulness) } \\
\hline \multirow{2}{*}{$\begin{array}{l}\text { The ability to improve a user's } \\
\text { mobility, allow for } \\
\text { independent movement across } \\
\text { difficult terrains }\end{array}$} & Not effective & Very Effective \\
\hline & $\begin{array}{l}\text { i.e. There was no improvement in user' } \\
\text { mobility }\end{array}$ & $\begin{array}{l}\text { i.e. Mobility is greatly } \\
\text { improved }\end{array}$ \\
\hline \multicolumn{3}{|c|}{ Implementability (sub-metric for Usefulness) } \\
\hline \multirow{2}{*}{$\begin{array}{l}\text { How implementable is the } \\
\text { design of today's technology? }\end{array}$} & Not implementable & Practically implementable \\
\hline & $\begin{array}{l}\text { i.e. Technological knowledge expertise } \\
\text { for industrializing this product is non- } \\
\text { existent }\end{array}$ & $\begin{array}{l}\text { i.e. There is established know- } \\
\text { how across various products }\end{array}$ \\
\hline
\end{tabular}

\section{Results}

This experiment yielded 192 sketches from student designers and data outliers were retained in the analysis as they presented natural variance in participant responses. The Shapiro-Wilk test was conducted to ascertain a normal distribution across the sample. Both outcome indices were not normally distributed $(\mathrm{p}<0.05)$. The null hypothesis for homogeneity of variance was rejected $(\mathrm{p}<0.05)$, the variance was deemed to not be normally distributed and the assumption of homoscedasticity was violated. As such, the non-parametric equivalent to a one-way between-groups analysis of variance (ANOVA), Kruskal-Wallis used instead. 
Table 2. Categorization of variables and the coding system for the observations sampling

\begin{tabular}{|l|l|l|l|}
\hline Brief and Stimuli Received & Variable Name & Sample Size (N) & Missing \\
\hline Control Brief only & C & 57 & 1 \\
\hline Control + Abstraction & AB & 72 & 1 \\
\hline Control + Physical Examples & P & 63 & 9 \\
\hline
\end{tabular}
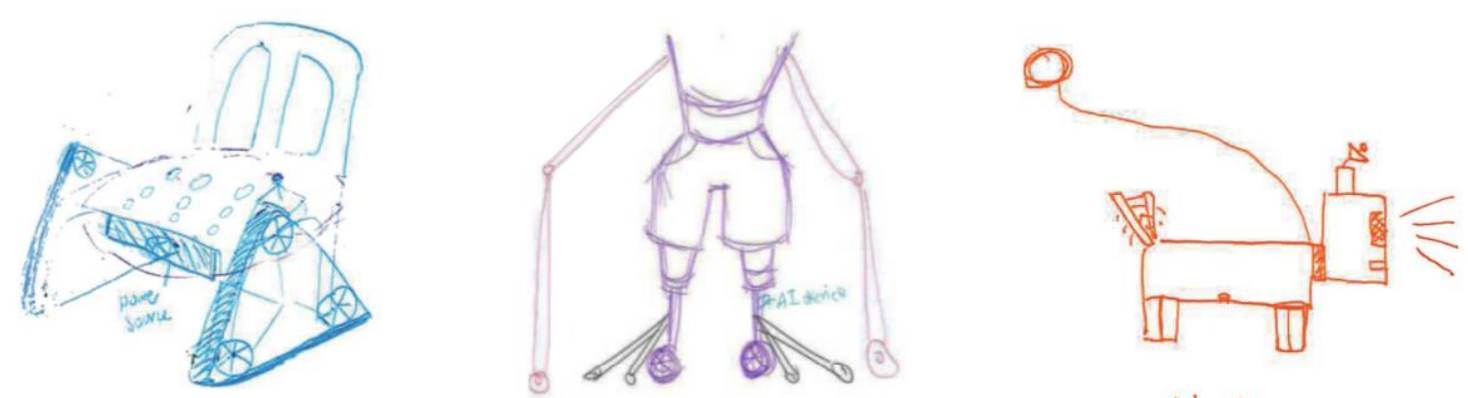

$$
\text { tobo-doggo }
$$

Figure 4. Sketches with varying degrees of novelty and usefulness scores; low novelty and high usefulness (left); high novelty and usefulness (middle); and high novelty and low usefulness (right)

\subsection{Novelty}

In examining the differences between the classes using the Kruskal-Wallis Test, it was pointed out that Novelty scores were significantly affected by the different stimulus $H(2, \mathrm{n}=181)=32.89, \mathrm{p}<.05$. Those in the control brief (C) recorded a higher median score that the other three briefs groups (see boxplots of Figure 1), achieving higher scores for the top 25\% while no outliers and extreme scores observed. Abstract briefs fared the second-best performance and the Physical was the least favorable for novelty as realized from the boxplots.

Pairwise comparisons with adjusted p-values showed that there were no significant differences between Novelty scores when students received the abstract compared to when received the control (black lines in Figure 4). Significant differences occurred between physical compared to Control ( $\mathrm{p}$ $=.00, \mathrm{r}=4.99)$, or Abstract $(p=.00, r=3.49)$.

Independent-Samples Kruskal-Wallis Test

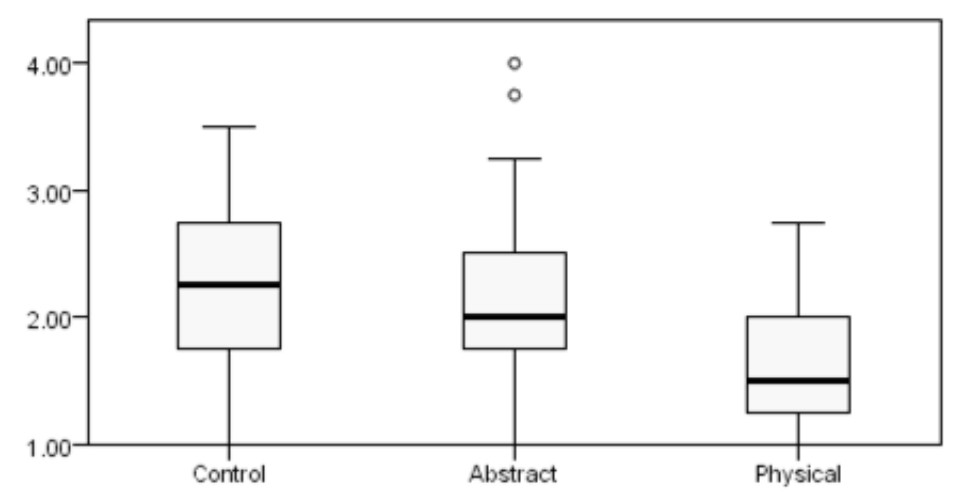

Pairwise Comparisons on Brief Conditions

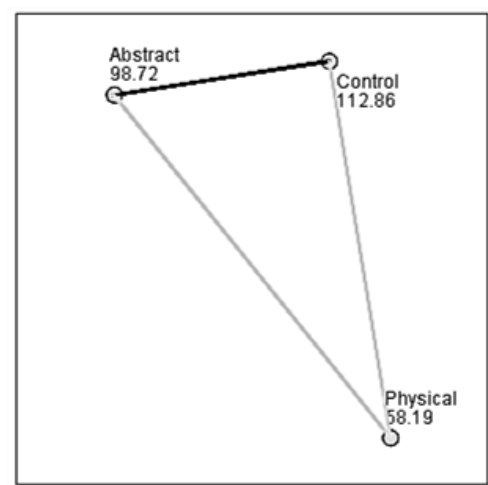

Figure 5. Proportion illustrations of novelty by brief conditions

\subsection{Usefulness}

The magnitude of the adjusted statistical significance of the average scores indicated that Usefulness scores were not significantly affected by the provision of different kinds of stimuli, $H(2, n=181)$ $\mathrm{p}=.120$, thus, retaining the null hypothesis. Scores in this metric were relatively close in terms of medians, with the $\mathrm{P}$ and $\mathrm{BL}$ ranked first, while $\mathrm{AB}$ was the least favorable for usefulness as realized 
from the boxplots in Figure 5. To sum up, none of the specific comparisons between groups indicates a significant difference in usefulness scores due to differing stimuli permutations. The results we received seem to mainly reflect the fact that abstraction seemed to lower Usefulness when compared to other groups, but all in all there were no statistically significant differences between the three groups with respect to this metric $(\mathrm{p}>0.05)$.

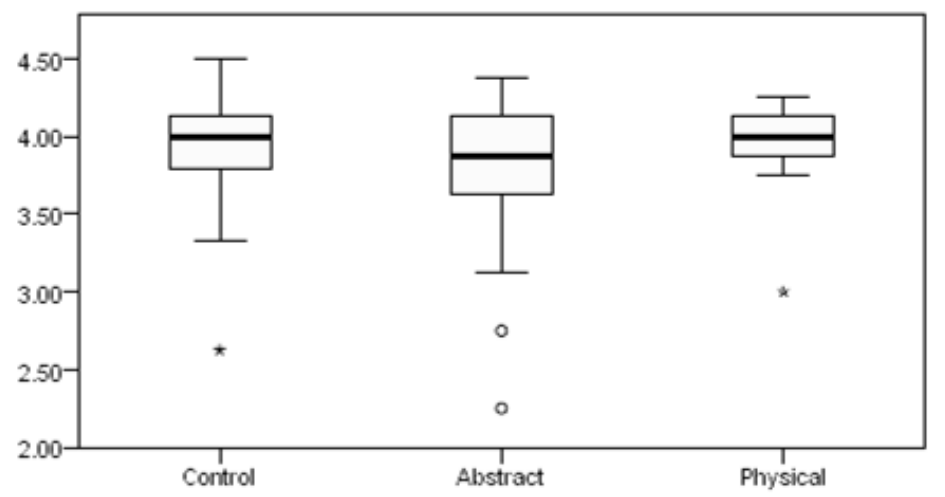

Figure 6. Proportion illustrations of usefulness by brief conditions

\subsection{Correlation analysis}

The survey showed that only 52 percent of the participants have used or assisted someone to use a mobility aid(s)/device(s) for the disabled (see appendix for description)

The Spearman rank-order correlation coefficients was carried out in the SPSS to assessing the existence of statistical relationships. The correlation coefficient $\mathrm{R}$ exceeding .415 is considered statistically significant at the .05 level (2-tailed).

It was observed that almost half of the participants were aware of mobility devices or interacted with them. However, among those who were aware of the product, there was no significant relationship between the number of participants that scored high on novelty and other briefs, but the Control. The rest of the briefs had mainly negative correlations, none of them significant though. Ultimately, no significant associations were found between the Usefulness metric and any of the survey responses.

Table 3. Spearman correlations between survey responses and creative outcomes $(n=100)$

\begin{tabular}{|c|c|c|c|}
\hline \multicolumn{2}{|c|}{ Condition } & Sig. (2-tailed) & Correlation \\
\hline \multirow{3}{*}{$\begin{array}{l}\text { 坖 } \\
0 \\
0 \\
z\end{array}$} & Control & $0.45^{*}$ & 0.05 \\
\hline & Abstract & -0.21 & 0.35 \\
\hline & Physical & -0.36 & 0.11 \\
\hline \multirow{3}{*}{ 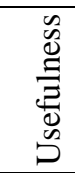 } & Control & -0.26 & 0.98 \\
\hline & Abstract & -0.18 & 0.43 \\
\hline & Physical & -0.02 & 0.94 \\
\hline
\end{tabular}

\section{Discussion}

This study aimed to answer two research questions, which revolved around the identification of determinants that enhanced the creativity metrics, novelty, and usefulness and their relationships with the product awareness to test if abstraction and concreteness yielded comparable results to those identified in the literature. The current study combined and tested the effects of different representations on the creative design outcomes

With respect to RQ1, findings highlighted that low-level fidelity stimuli, such as the provision of abstract information, have been identified to produce higher novelty scores. On the other hand, abstract representations yielded lower novelty compared to the control group. This finding is in line with the 
literature, where the exposure to concrete stimuli resulted in less novel ideas, while abstract representation yielded more novel ideas (Cheng et al., 2014), and help in counteracting fixation (Vasconcelos and Crilly, 2016). While some studies purported the positive relationship between textual stimuli and the originality of ideas, others found that images yielded improved results, while physical objects reduced the novelty and variety of final concepts (Toh and Miller, 2015). In our study, physical examples presented to students in the $\mathrm{P}$ class classified as a concrete representation that provided the participants with increased fidelity which were more beneficial in the generation of useful ideas. However, part of the claims by Toh and Miller (2015) requires further refinement, as indicated in our findings. Though physical examples were proven to influence the novelty of ideas negatively, further fine-tuning by categorizing physical objects based on their levels of specificity proves otherwise.

The increased specificities facilitated the transfer of ideas, as well as the improvisation and ideation processes. Hence, not all physical objects are negatively associated with novelty performances. Therefore, we can infer that the inclusion of more concrete stimuli like the physical example appears to steer the student designer away from potentially innovative or disruptive avenues. On the other hand, P is favorable for useful products. Similar attributes have been reported from our factorial study where a mix of contextual information with a physical example may be beneficial for usability nor for novelty (Koronis et al., 2019), where contextual information provides details about the importance of the product and health benefits. The studies of Linsey et al. (2010); (Heckler, 2010) also highlight abstract representations promote originality in ideas while concrete representations facilitate the reproduction of a product and create highly aligned, or useful design outcomes.

In response to RQ2, there were no statistically significant differences in the student (self-reported) awareness and the different groups besides the control group. This is a result indicating that having a high level of awareness of the domain will only assist the one that receives a succinct description of a brief (control brief). The effect we got seems to mainly reflect also the fact that students who are familiar with the product will contribute more useful than novel ideas. Perhaps, additional information is fixating the designer; thus they tend to produce less novel examples because of this phenomenon (Jansson and Smith, 1991).

\section{Conclusions and future work}

This study suggests that the more concrete brief content becomes (physical brief), the less creative ideas can be generated in the form of novelty. The implications of this work can strongly impact the formulation of design briefs where the goal is to stimulate the creativity of design outcomes and examine their relationships to product awareness. In assessing the determinants that enhance creativity, our study identified abstract representations with low levels of specificity as negatively influencing the usefulness scores and novelty scores.

A post-sketch survey was integrated to assess their prior knowledge and their downstream impact on the creative outcomes, highlighting that there is no clear relationship between the product awareness of student designer teams and the creativity of their concept sketches. This is an assuring finding that potentially allows for more flexibility in the design team configurations. In that sense, not all of the group members will have to have prior experience with the product that they will be designing for in order to ensure high-quality outcomes.

In future iterations of this research, design briefs and associated quantitative, physical, contextual and visual stimuli may be altered to test out other iterations that yield success in creativity scores. Using semantic analysis, future studies may look deeper into why and how abstract and concrete stimuli interact to influence creativity scores by analysing the participant input (written comments) from the sketching exercises. We would go more in-depth into understanding cognition mechanisms, through semantic analysis to uncover more in-depth insights into influences on creativity outcomes and at participant perceptions and profiles.

\section{Limitations}

These findings collected from first-year students embark on this activity with no prior design knowledge, therefore this can limit the extension of these results to experienced students and/or professional designers. Nonetheless, we provide the impetus for future research to the existing 
findings by testing the representations in combination and measuring the effect between the brief and the respective representations.

\section{Acknowledgment}

This work is supported by the Singapore University of Technology and Design (SUTD) and the SUTD-MIT International Design Centre (IDC, idc.sutd.edu.sg), project IDG 11600102.

\section{References}

Amabile, T.M. (1996), Creativity in Context, 1st ed., Westview Press, Boulder, CO.

Baer, J. (2008), "Commentary: divergent thinking tests have problems, but this is not the solution", Psychology of Aesthetics, Creativity, and the Arts, Vol. 2 No. 2, pp. 89-92.

Bourgeois-Bougrine, S. et al. (2017), "Engineering students' use of creativity and development tools in conceptual product design: What, when and how?", Thinking Skills and Creativity, Vol. 24, pp. 104-117. https://dx.doi.org/10.1016/j.tsc.2017.02.016

Camburn, B.A. et al. (2017), "Design Innovation: A Study of Integrated Practice." Ohio, USA, August 6-9.

Carlgren, L., Rauth, I. and Elmquist, M. (2016), "Framing Design Thinking: The Concept in Idea and Enactment", Creativity and Innovation Management, Vol. 25 No. 1, pp. 38-57. https://dx.doi.org/10.1111/ caim. 12153

Cheng, P., Mugge, R. and Schoormans, J.P.L. (2014), "A new strategy to reduce design fixation: Presenting partial photographs to designers", Design Studies, Vol. 35 No. 4, pp. 374-391. https://doi.org/10.1016/ j.destud.2014.02.004

Dean, D.L. et al. (2006), "Identifying Quality, Novel, and Creative Ideas: Constructs and Scales for Idea Evaluation", Journal of the Association for Information Systems, Vol. 7 No. 10, pp. 646-699.

Genco, N., Hölttä-Otto, K. and Seepersad, C.C. (2012), "An Experimental Investigation of the Innovation Capabilities of Undergraduate Engineering Students", Journal of Engineering Education, Vol. 101 No. 1, pp. 60-81. https://dx.doi.org/10.1002/j.2168-9830.2012.tb00041.x

Goldschmidt, G. and Smolkov, M. (2006), "Variances in the impact of visual stimuli on design problem solving performance”, Design Studies, Vol. 27 No. 5, pp. 549-569. https://dx.doi.org/10.1016/j.destud.2006.01.002

Goldstone, R. and Sakamoto Y. (2003), The transfer of abstract principles governing complex adaptive systems. Vol. 46.

Gonçalves, M., Cardoso, C. and Badke-Schaub, P. (2016), "Inspiration choices that matter: the selection of external stimuli during ideation”, Design Science, Vol. 2, p. e10. https://dx.doi.org/10.1017/dsj.2016.10

Goucher-Lambert, K., Moss, J. and Cagan, J. (2019), "A neuroimaging investigation of design ideation with and without inspirational stimuli-understanding the meaning of near and far stimuli”, Design Studies, Vol. 60, pp. 1-38. https://doi.org/10.1016/j.destud.2018.07.001

Heckler, A.F. (2010), "Concrete vs. abstract problem formats: a disadvantage of prior knowledge".

Holyoak, K.J. and Thagard, P. (1989), "Analogical Mapping by Constraint Satisfaction”, Cognitive Science, Vol. 13 No. 3, pp. 295-355. https://dx.doi.org/10.1207/s15516709 $\operatorname{cog} 1303 \_1$

Howard, T.J., Dekoninck, E.A. and Culley, S.J. (2010), "The use of creative stimuli at early stages of industrial product innovation", Research in Engineering Design, Vol. 21 No. 4, pp. 263-274. https://dx.doi.org/ 10.1007/s00163-010-0091-4

Jansson, D.G. and Smith, S.M. (1991), "Design fixation", Design Studies, Vol. 12 No. 1, pp. 3-11. https://doi.org/10.1016/0142-694X(91)90003-F

Johnson, S., Kang, L. and Akil, H.M. (2016), "Mechanical Behavior of Jute Hybrid Bio-Composites", Composites Part B: Engineering, Vol. 91, pp. 83-93. http://dx.doi.org/10.1016/j.compositesb.2015.12.052

Kampylis, P.G. and Valtanen, J. (2010), "Redefining Creativity - Analyzing Definitions, Collocations, and Consequences", The Journal of Creative Behavior, Vol. 44 No. 3, pp. 191-214. https://dx.doi.org/ 10.1002/j.2162-6057.2010.tb01333.x

Kang, K. S. J. et al. (2018), "Exploring the use of a full factorial design of experiment to study design briefs for creative ideation", ASME-IDETC, Quebec, Canada, August 26-29.

Koronis, G. et al. (2019), "An Empirical Study on the Impact of Design Brief Information on the Creativity of Design Outcomes with consideration of Gender, and Gender Diversity", Journal of Mechanical Design, Vol. 141 No. 7, pp. 071102-14. https://dx.doi.org/10.1115/1.4043207

Lawson, R.B. (2006), How designers think: The Design Process Demystified, Butterworth Architecture, Jordan Hill, Oxford.

Lievens, F., De Corte, W. and Westerveld, L. (2012), "Understanding the Building Blocks of Selection Procedures: Effects of Response Fidelity on Performance and Validity", Journal of Management, Vol. 41 No. 6, pp. 1604-1627. https://dx.doi.org/10.1177/0149206312463941 
Linsey, J.S., Markman, A.B. and Wood, K.L. (2012), "Design by Analogy: A Study of the WordTree Method for Problem Re-Representation", Journal of Mechanical Design, Vol. 134 No. 4. https://dx.doi.org/ $10.1115 / 1.4006145$

Linsey, J.S. et al. (2010), “A Study of Design Fixation, Its Mitigation and Perception in Engineering Design Faculty", Journal of Mechanical Design, Vol. 132 No. 4, pp. 1-12. https://dx.doi.org/10.1115/1.4001110

Marschark, M. and Paivio, A. (1977), "Integrative processing of concrete and abstract sentences", Journal of Verbal Learning and Verbal Behavior, Vol. 16 No. 2, pp. 217-231. https://doi.org/10.1016/S00225371(77)80048-0

Runco, M.A. and Jaeger, G.J. (2012), “The Standard Definition of Creativity”, Creativity Research Journal, Vol. 24 No. 1, pp. 92-96. https://dx.doi.org/10.1080/10400419.2012.650092

Shah, J.J., Smith, S.M. and Vargas-Hernandez, N. (2003), "Metrics for measuring ideation effectiveness", Design Studies, Vol. 24 No. 2, pp. 111-134. https://dx.doi.org/10.1016/S0142-694X(02)00034-0

Shai, O. et al. (2013), "Creativity and scientific discovery with infused design and its analysis with C-K theory", Research in Engineering Design, Vol. 24 No. 2, pp. 201-214. https://dx.doi.org/10.1007/s00163-012-0137-X

Sosa, R., Vasconcelos L.A. and Cardoso C.C. (2018), "Design briefs in creativity studies", ICDC, Bath, UK, Jan 31-Feb 2.

Studer, J. et al. (2016), Cognitive Heuristics in Defining Engineering Design Problems.

Toh, C.A. and Miller, S.R. (2015), "How engineering teams select design concepts: A view through the lens of creativity", Design Studies, Vol. 38, pp. 111-138. https://dx.doi.org/10.1016/j.destud.2015.03.001

Vasconcelos, L.A., et al. (2017), "Inspiration and Fixation: The Influences of Example Designs and System Properties in Idea Generation”, Journal of Mechanical Design, Vol. 139 No. 3, pp. 031101-13. https://dx.doi.org/10.1115/1.4035540

Vasconcelos, L.A. and Crilly, N. (2016), "Inspiration and fixation: Questions, methods, findings, and challenges", Design Studies, Vol. 42, pp. 1-32. https://doi.org/10.1016/j.destud.2015.11.001

Viswanathan, V. and Linsey J. (2012), Physical Models and Design Thinking: A Study of Functionality, Novelty and Variety of Ideas. Vol. 134.

Zahner, D. et al. (2010), "A fix for fixation? Rerepresenting and abstracting as creative processes in the design of information systems", Artificial Intelligence for Engineering Design, Analysis and Manufacturing, Vol. 24 No. 2, pp. 231-244. https://dx.doi.org/10.1017/S0890060410000077

\section{Appendix - Survey items and descriptive}

Q1: Please tell us your gender

\begin{tabular}{|l|l|l|l|}
\hline \multicolumn{2}{|l|}{ Brief Condition } & Frequency & Percent \\
\hline \multirow{3}{*}{ P } & Male & 13 & 61.90 \\
\cline { 2 - 4 } & Female & 8 & 38.10 \\
\cline { 2 - 4 } & Total & 21 & 100.00 \\
\hline \multirow{3}{*}{ BL } & Male & 15 & 75.00 \\
\cline { 2 - 4 } & Female & 5 & 25.00 \\
\cline { 2 - 4 } & Total & 20 & 100.00 \\
\hline AB & Male & 13 & 54.20 \\
\cline { 2 - 4 } & Female & 11 & 45.80 \\
\cline { 2 - 4 } & Total & 24 & 100.00 \\
\hline
\end{tabular}

Q2: Have you ever used or assisted someone to use a mobility aid(s)/device(s) for the disabled?

\begin{tabular}{|l|l|c|c|c|c|}
\hline \multicolumn{2}{|l|}{$\begin{array}{l}\text { Product } \\
\text { Awareness } \\
\text { Descriptive }\end{array}$} & \multicolumn{2}{|c|}{ Yes } & \multicolumn{2}{c|}{ No } \\
\cline { 2 - 6 } & Count & $\begin{array}{c}\text { Row N } \\
\%\end{array}$ & Count & $\begin{array}{c}\text { Row N } \\
\%\end{array}$ \\
\hline \multirow{3}{*}{} & Baseline & 10 & $50.0 \%$ & 10 & $50.0 \%$ \\
\cline { 2 - 6 } & Abstract & 7 & $31.8 \%$ & 15 & $68.2 \%$ \\
\cline { 2 - 6 } & Physical & 14 & $66.7 \%$ & 7 & $33.3 \%$ \\
\cline { 2 - 6 } & Total & 31 & $49.2 \%$ & 32 & $50.8 \%$ \\
\hline
\end{tabular}

